\title{
Chemotherapy continuity and incidence of febrile neutropenia with CHOP therapy in an outpatient setting
}

\author{
EISEKI USAMI ${ }^{1}$, MICHIO KIMURA ${ }^{1}$, MINA IWAI $^{1}$, SHOYA TAKENAKA ${ }^{1}$, \\ HITOMI TERAMACHI $^{2}$ and TOMOAKI YOSHIMURA ${ }^{1}$ \\ ${ }^{1}$ Department of Pharmacy, Ogaki Municipal Hospital, Ogaki-shi, Gifu 503-8502; \\ ${ }^{2}$ Clinical Pharmacy, Gifu Pharmaceutical University, Gifu-shi, Gifu 501-1196, Japan
}

Received August 26, 2015; Accepted December 7, 2015

DOI: $10.3892 / \mathrm{mco} .2016 .738$

\begin{abstract}
The cyclophosphamide, doxorubicin, vincristine and prednisolone (CHOP) regimen is considered to be a standard treatment for non-Hodgkin's lymphoma (NHL). Patients receiving CHOP chemotherapy often experience febrile neutropenia (FN) due to myelotoxicity. The proper management of FN is essential to guarantee a positive outcome of the NHL treatment. Therefore, the present study retrospectively examined chemotherapy continuity and the incidence of FN during CHOP therapy in an outpatient setting. The subjects were 136 patients who received CHOP chemotherapy between January 2012 and December 2014. A total of 31 patients unable to be treated in an outpatient setting were excluded from the study. Of the remaining 105 patients, 73 patients who did not require hospitalization during the chemotherapy treatment were included in the non-hospitalized group, and 32 patients who required hospitalization during chemotherapy treatment were included in the re-hospitalization group. The numbers of patients from these two groups who completed the planned treatment were 71 and 24 , respectively $(\mathrm{P}<0.01)$. In addition, the duration of granulocyte-colony stimulating factor (G-CSF) treatment was $5.3 \pm 1.22$ and $6.1 \pm 1.46$ days, respectively $(\mathrm{P}<0.01)$. The numbers of patients experiencing FN in an outpatient setting were 14 and 19 , respectively $(\mathrm{P}<0.01)$. During administration of primary prophylaxis with G-CSF, the incidence of FN was $21.0 \%$ (22/105) in cycle 1 . In conclusion, the present study has revealed a requirement to educate patients about infection prevention prior to the first cycle of chemotherapy. Patients who require the administration of long- term G-CSF are at risk of unplanned re-hospitalization, and treating them with polyethylene glycol G-CSF to reduce the number of required injections should be considered as an option. Therefore, proper supportive
\end{abstract}

Correspondence to: Mr. Eiseki Usami, Department of Pharmacy, Ogaki Municipal Hospital, 4-86 Minaminokawa-cho, Ogaki-shi, Gifu 503-8502, Japan

E-mail: omhp2002@yahoo.co.jp

Key words: CHOP, febrile neutropenia, outpatient, re-hospitalization, chemotherapy continuity therapy and management of infection are important to safely treat patients with $\mathrm{CHOP}$ in an outpatient setting.

\section{Introduction}

Over time, the administration of chemotherapy has moved from an inpatient to an outpatient setting. Over $95 \%$ of patients with solid tumors, including those with breast or colorectal cancers, are treated in an outpatient setting. However, only $30 \%$ of the patients with hematological malignancies are treated in an outpatient setting, due to intensive myelotoxicity or daily administration regimens. A regimen of cyclophosphamide, doxorubicin, vincristine and prednisolone (CHOP) is considered to be a standard treatment for non-Hodgkin's lymphoma (NHL). Although CHOP therapy leads to intensive myelosuppression, an increasing number of patients are being treated in an outpatient setting. It is important that NHL patients receive the full chemotherapy regimen, since the survival rate may be markedly decreased when CHOP chemotherapy is delivered at $<90 \%$ of the planned relative dose intensity (RDI) $(1,2)$. Therefore, prophylactic administration of granulocyte-colony stimulating factor (G-CSF) is recommended for NHL patients.

Patients receiving CHOP therapy often experience febrile neutropenia (FN) due to myelotoxicity. The presence of FN necessitates a reduction in the planned RDI, and also leads to hospitalization with the administration of antibiotics (3). The prompt administration of antibiotics is crucial, since infection can progress rapidly. Although varying degrees of FN have been reported, the general risk factors for FN are well known, and include an older age, advanced disease, poor performance status (PS), comorbidities, baseline hemoglobin and body surface area (4-7). The proper management of FN is essential to maintain the RDI and to guarantee a positive outcome of the NHL treatment. Therefore, the present study retrospectively examined chemotherapy continuity and incidence of FN with CHOP therapy in an outpatient setting.

\section{Subjects and methods}

Subjects. The subjects were 136 patients who received CHOP chemotherapy at Ogaki Municipal Hospital (Ogaki-shi, Japan) between January 2012 and December 2014. The first cycle of CHOP chemotherapy was administered in an inpatient setting for 
all patients, and the treatment was moved to an outpatient setting based on a consideration of the patient's condition. A total of 31 patients were excluded since they were unable to be moved to an outpatient treatment setting. Of the remaining 105 patients, 32 $(30.5 \%)$ were assigned to the re-hospitalization group, who required hospitalization again during the chemotherapy treatment in an outpatient setting, and 73 (69.5\%) were assigned to the non-hospitalization group, who did not require hospitalization until after the patients had finished their outpatient chemotherapy (Fig. 1). The CHOP regimen $\left[750 \mathrm{mg} / \mathrm{m}^{2}\right.$ cyclophosphamide, $50 \mathrm{mg} / \mathrm{m}^{2}$ doxorubicin and $1.4 \mathrm{mg} / \mathrm{m}^{2}$ vincristine, all on day 1 ; and $100 \mathrm{mg} /$ body or $60 \mathrm{mg} / \mathrm{m}^{2}$ (for patients $>65$ years) prednisolone daily for 5 days] was administered every 3 weeks. The present study was reviewed and approved by the Ethics Committee at Ogaki Municipal Hospital.

Characteristics of the subjects. The characteristics of the subjects treated with CHOP therapy in an outpatient setting were investigated. Gender, age, histology, clinical stage, PS [Eastern Cooperative Oncology Group (ECOG) (8)], B symptoms, chemotherapy treatment times, doses and RDI, the total cycles, planned treatment completion, duration of treatment with G-CSF, nadir [day, white blood cell (WBC) and neutrophil count] and the presence of FN were compared between the re-hospitalization and non-hospitalization groups.

Incidence of FN in an outpatient setting. Incidences of FN were compared between the re-hospitalization and non-hospitalization groups in an outpatient setting.

Timing of FN occurrence. The timing of FN during the CHOP treatment cycle was examined.

Investigation of the factors affecting re-hospitalization. The factors affecting re-hospitalization during treatment in an outpatient setting were examined.

Causes of re-hospitalization. The factors affecting re-hospitalization during outpatient treatment were investigated.

Statistical analysis. The data were analyzed using JMP software (version 5.0.1J; SAS Institute Japan Ltd., Tokyo, Japan). The Mann-Whitney U test was used for comparison of the backgrounds of the subjects between the groups. The recorded $\mathrm{P}$-values were two-sided, and $\mathrm{P}<0.05$ was considered to indicate a statistically significant difference. The areas under the receiver-operator characteristic (ROC) curves were calculated to estimate the accuracy and cut-off values for the continuous variables obtained by univariate logistic regression analysis. Subsequently, the data were analyzed using multivariate logistic regression analysis.

\section{Results}

Characteristics of the subjects. Table I summarizes the background characteristics of the subjects. The numbers of patients in the non-hospitalization and re-hospitalization groups were 73 and 32, respectively, of which 71 and 24 completed the planned treatment, respectively (therefore, 2 and 8 , respectively, did not complete the treatment). In addition, the duration of the

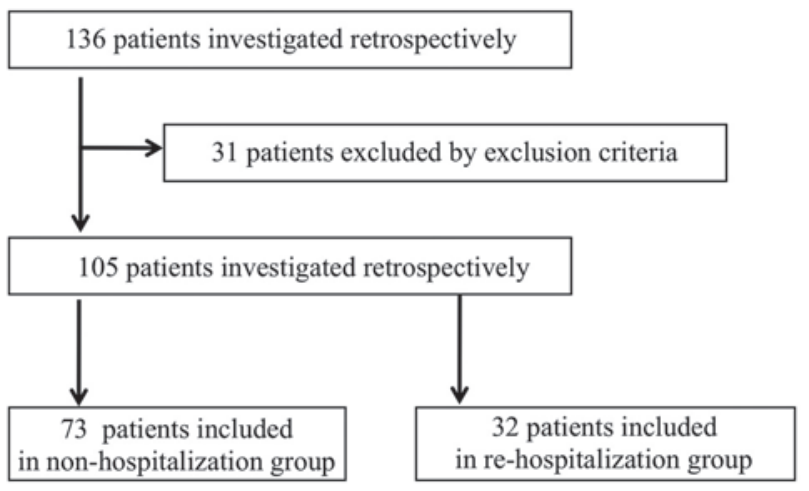

Figure 1. Subject selection and number of subjects analyzed.

G-CSF treatment was $5.3 \pm 1.22$ and $6.1 \pm 1.46$ days, respectively. The numbers of patients who experienced FN were 14 and 19, respectively.

Incidence of FN in an outpatient setting. Overall, 31.4\% (33/105) of patients receiving CHOP therapy experienced $\mathrm{FN}$ at a certain point during the present study. Among these, a total of $18.1 \%(19 / 105)$ of the patients experienced FN in an outpatient setting, and 9.5\% (10/105) experienced it for the first time in an outpatient setting. Additionally, $8.6 \%$ (9/105) of the patients experienced more than two episodes of FN during all the chemotherapy cycles.

Timing of FN occurrence. FN occurred in $21.0 \%(22 / 105)$ of the patients during cycle $1,2.9 \%(3 / 105)$ in cycle $2,4.8 \%(5 / 104)$ in cycle $3,5.6 \%(5 / 89)$ in cycle $4,6.9 \%(6 / 87)$ in cycle $5,2.4 \%(2 / 83)$ in cycle 6 and $0 \%(0 / 46)$ of the patients in cycles 7 and 8 .

Investigation of the factors affecting re-hospitalization. A total of 14 factors affecting re-hospitalization from an outpatient setting were analyzed using univariate logistic regression analysis. The independent variables of the dosage data were analyzed as continuous variables, and the results are shown in Table II. The average duration of G-CSF treatment [odds ratio (OR), 25.73; 95\% confidence interval (CI), 2.68-308.29; $\mathrm{P}<0.01]$, incidence of FN (OR, 4.77; 95\% CI, 1.95-12.08; $\mathrm{P}<0.01)$, and patients who could not complete the planned treatment (OR, 11.83; $95 \%$ CI, 2.74-82.09; $\mathrm{P}<0.01)$ demonstrated significant differences between the non-hospitalization and re-hospitalization groups. The area under the ROC curve of the average duration of G-CSF treatment was 0.67 , and the cut-off value was 5.5 days. Table III shows the results of the multivariate analysis based on the factors affecting re-hospitalization, with $\mathrm{P}<0.25$ by univariate logistic regression analysis. This analysis revealed that the incidence of FN (OR, 4.61; 95\% CI, 1.68-13.19; $\mathrm{P}<0.01)$ and unreached planned treatment (OR, 11.81; 95\% CI, 2.07-99.74; $\mathrm{P}<0.01)$ were independent factors that significantly contributed to re-hospitalization.

Causes of re-hospitalization. The cause of hospitalization with respect to the 32 re-hospitalization patients was $\mathrm{FN}$ in $59.4 \%$ $(19 / 32)$ of the patients, delayed WBC recovery in $12.5 \%(4 / 32)$, Pneumocystis carinii pneumonia in $9.4 \%$ (3/32), pneumonia in $9.4 \%(3 / 32)$, a decline in PS in $6.3 \%(2 / 32)$, and heart failure in $3.1 \%(1 / 32)$ of the patients. 
Table I. Baseline characteristics of the patients.

\begin{tabular}{|c|c|c|c|}
\hline & Non-hospitalization & Re-hospitalization & P-value \\
\hline No. of patients & 73 & 32 & \\
\hline Gender & & & 0.11 \\
\hline Male & 31 & 19 & \\
\hline Female & 42 & 13 & \\
\hline Age, median (years) & 66.0 & 73.0 & 0.17 \\
\hline Range & $(37-93)$ & $(18-87)$ & \\
\hline \multicolumn{4}{|l|}{ Histology } \\
\hline Diffuse large B-cell lymphoma & 38 & 17 & \\
\hline Follicular lymphoma & 12 & 6 & \\
\hline T-cell lymphoma & 3 & 1 & \\
\hline Mucosa-associated lymphoid tissue lymphoma & 10 & 3 & \\
\hline Mantle cell lymphoma & 4 & 2 & \\
\hline Others & 6 & 3 & \\
\hline Clinical stage (Ann Arbor staging) ${ }^{\mathrm{a}}$ & & & 0.41 \\
\hline I & 16 & 3 & \\
\hline II & 13 & 6 & \\
\hline III & 13 & 8 & \\
\hline IV & 31 & 15 & \\
\hline Performance status (ECOG) & & & 0.11 \\
\hline 0 & 62 & 22 & \\
\hline 1 & 5 & 6 & \\
\hline 2 & 6 & 3 & \\
\hline 3 & 0 & 1 & \\
\hline 4 & 0 & 0 & \\
\hline B symptoms & & & 0.32 \\
\hline Present & 9 & 2 & \\
\hline Absent & 64 & 30 & \\
\hline \multicolumn{4}{|l|}{ Chemotherapy } \\
\hline Treatment times, media (range) & $6(3-8)$ & $6(2-8)$ & 0.49 \\
\hline Treatment dose $(\%)$, median (range) & $100(70-100)$ & $100(80-100)$ & 0.71 \\
\hline RDI, median (range) & $0.93(0.62-1.00)$ & $0.9(0.61-1.00)$ & 0.22 \\
\hline Total cycles of CHOP & & & 0.49 \\
\hline 2 & 0 & 1 & \\
\hline 3 & 14 & 1 & \\
\hline 4 & 1 & 1 & \\
\hline 5 & 0 & 4 & \\
\hline 6 & 27 & 10 & \\
\hline 7 & 0 & 1 & \\
\hline 8 & 31 & 14 & \\
\hline Planned treatment & & & $<0.01$ \\
\hline Completion & 71 & 24 & \\
\hline Unreached & 2 & 8 & \\
\hline \multicolumn{4}{|l|}{ G-CSF } \\
\hline Duration of treatment (days), mean \pm SD & $5.3 \pm 1.22$ & $6.1 \pm 1.46$ & $<0.01$ \\
\hline Duration of treatment (days), median (range) & $5(3-8)$ & $5(4-14)$ & 0.01 \\
\hline \multicolumn{4}{|l|}{ Nadir } \\
\hline Day, median (range) & $11(6-16)$ & $11(7-16)$ & 0.07 \\
\hline WBC (per $\mu 1)$, median (range) & $1230(260-8180)$ & $1395(50-6080)$ & 0.86 \\
\hline Neutrophil (per $\mu 1)$, median (range) & $357(15-7443)$ & $378(6-4013)$ & 0.44 \\
\hline
\end{tabular}


Table I. Continued.

\begin{tabular}{|c|c|c|c|}
\hline & Non-hospitalization & Re-hospitalization & P-value \\
\hline $\mathrm{FN}$ & & & $<0.01$ \\
\hline Present & 14 & 19 & \\
\hline Absent & 59 & 13 & \\
\hline
\end{tabular}

${ }^{\mathrm{a}}$ For further details on Ann Harbor staging, see Ref (9). Data are presented as $\mathrm{n}$ or the median (range) or the mean \pm SD ( $\left.\mathrm{n}=105\right)$. RDI, relative dose intensity; CHOP, cyclophosphamide, doxorubicin, vincristine, prednisolone; G-CSF, granulocyte colony-stimulating factor; WBC, white blood cell; FN, febrile neutropenia, S.D., standard deviation. A B symptom is any systemic finding associated with lymphomas which is a clinical systemic condition.

Table II. Univariate analysis of factors affecting re-hospitalization from an outpatient setting $(\mathrm{n}=103)$

\begin{tabular}{|c|c|c|c|c|c|}
\hline Factor & OR & $95 \% \mathrm{CI}$ & $P$ value & AUC & Cut-off \\
\hline Duration of G-CSF treatment (days) & 25.73 & $2.68-308.29$ & $<0.01$ & 0.67 & 5.5 \\
\hline Gender (female) & 0.51 & $0.21-1.16$ & 0.11 & & \\
\hline Age & 7.21 & $0.47-144.71$ & 0.17 & & \\
\hline $\mathrm{PS} \geq 2$ & 0.62 & $0.16-2.61$ & 0.49 & & \\
\hline Chemotherapy treatment time & 1.63 & $0.41-7.34$ & 0.51 & & \\
\hline Chemotherapy RDI & 0.36 & $0.06-1.89$ & 0.22 & & \\
\hline Chemotherapy treatment dose (\%) & 1.43 & $0.26-11.26$ & 0.71 & & \\
\hline Day of nadir (days) & 0.13 & $0.01-1.19$ & 0.08 & & \\
\hline White blood cell count of nadir (per $\mu 1$ ) & 0.79 & $0.03-10.97$ & 0.86 & & \\
\hline Neutrophil count of nadir (per $\mu 1)$ & 0.32 & $0.01-4.75$ & 0.47 & & \\
\hline Incidence of FN & 4.77 & $1.95-12.08$ & $<0.01$ & & \\
\hline Clinical stage $\geq 3$ (Ann Arbor) & 0.59 & $0.23-1.43$ & 0.25 & & \\
\hline B symptoms present & 2.11 & $0.51-14.39$ & 0.35 & & \\
\hline Unreached planned treatment & 11.83 & $2.74-82.09$ & $<0.01$ & & \\
\hline
\end{tabular}

OR, odds ratio; CI, confidence interval; AUC, area under the curve; G-CSF, granulocyte colony-stimulating factor; PS, performance status; RDI, relative dose intensity; FN, febrile neutropenia.

Table III. Multivariate analysis of factors affecting re-hospitalization from an outpatient setting $(\mathrm{n}=103)$.

\begin{tabular}{lccc}
\hline Factor & OR & $95 \%$ CI & P-value \\
\hline Duration of G-CSF treatment ( $\geq 5.5$ days) & 0.21 & $0.17-1.42$ & 0.20 \\
Female & 0.43 & $0.15-1.17$ & 0.11 \\
Age & 0.48 & $0.01-17.76$ & 0.67 \\
Chemotherapy RDI & 0.51 & $0.06-4.01$ & 0.51 \\
Day of nadir (days) & 0.33 & $0.02-4.97$ & 0.43 \\
Incidence of FN & 4.61 & $1.68-13.19$ & $<0.01$ \\
Unreached planned treatment & 11.81 & $2.07-99.74$ & $<0.01$
\end{tabular}

OR, odds ratio; CI, confidence interval; G-CSF, granulocyte colony-stimulating factor; RDI, relative dose intensity; FN, febrile neutropenia.

\section{Discussion}

The chemotherapy regimens used for patients with NHL are often dose-intensive, with high rates of associated neutropenic-related morbidity and occasional mortality (3).
In the present study, grade 4 neutropenia occurred in $70.5 \%$ (74/105) of the patients, with grade 3 occurring in $20.0 \%$ $(21 / 105)$ of the patients. Over $90 \%$ of the patients experienced serious hematological toxicity. The myelotoxic regimen often results in $\mathrm{FN}$, which is the most serious 
hematological toxicity $(10,11)$. Hospitalization and prompt administration of antibiotics are necessary for patients with FN, since the infection can progress rapidly. Additionally, FN increases medical costs and may lead to delays in the treatment schedule and reductions in chemotherapy delivery. In the present study, $43.4 \%(59 / 136)$ of all patients receiving CHOP therapy experienced $\mathrm{FN}$ at a certain point during the study. The FN occurrence rate of the patients who could be treated in an outpatient setting was $31.4 \%$ (33/105), which is notably high. Furthermore, $22.8 \%(31 / 136)$ of the patients could not be treated in an outpatient setting, and $83.9 \%$ (26/31) of these experienced FN. Almost all these patients experienced long- term hospitalization and unreached treatment. The CHOP regimen is regarded as an intermediate risk for $\mathrm{FN}$, with an occurrence rate of $10-20 \%$ recorded in the National Comprehensive Cancer Network and the European Organization for Research and Treatment of Cancer guidelines (4). However, several studies have previously reported an $\mathrm{FN}$ occurrence rate of $28-58 \%$ among NHL patients $(5,12-14)$, suggesting that the CHOP regimen itself poses a high risk for $\mathrm{FN}$ in a real clinical situation.

Initially, CHOP chemotherapy was administered in an inpatient setting to gauge the possible adverse events. The FN occurrence rate for patients who received the $\mathrm{CHOP}$ regimen with primary prophylaxis of G-CSF was $17-22 \%(13,15,16)$. G-CSF primary prophylaxis was administered in $90.6 \%$ of the patients in the present study. The FN occurrence rate of patients in cycle 1 was $21.0 \%(22 / 105)$. In agreement with a report by Mayordomo et al (17), 53.7\% of all FN events (22/41) occurred during cycle 1 . Lyman et al (18) reported that a lack of primary prophylaxis with G-CSF in cycle 1 was associated with an increased risk of FN (18). However, although primary prophylaxis of G-CSF for almost all patients was administered in the present study, the FN occurrence rate in cycle 1 was the highest of all the treatment cycles. This result suggests that it is necessary to educate patients about FN prior to the first chemotherapy cycle.

Pegfilgrastim (Peg-G) comprises the protein filgrastim, to which a polyethylene glycol (Peg) molecule is bound covalently to the $\mathrm{N}$-terminal methionine residue $(19,20)$. It was first approved in the United States in 2002, and approved for use in Japan in November 2014. The addition of the Peg molecule increases the serum half-life of Peg-G, thus requiring fewer injections compared with unmodified G-CSF. In the present study, the duration of G-CSF treatment was longer in the re-hospitalization group compared with the non-hospitalization group $(\mathrm{P}<0.01)$. Since Peg-G was not used in the present study, a daily administration of $\mathrm{G}-\mathrm{CSF}$ was required, in spite of severe neutropenia and the risk of infection in the outpatient setting. Requiring only one subcutaneous injection per cycle, Peg-G may be more convenient, and pose less of a risk, for the patient. It may become the standard of care to maintain the patients' quality of life, and to reduce the occurrence of FN.

Unplanned re-hospitalizations occurred in 30.5\% (32/105) of the patients, which was due to FN or pneumonia in $\sim 80 \%$ of the patients. Pettengell et al (15) reported a similar rate of re-hospitalization. The incidence of $\mathrm{FN}$ is an independent factor significantly contributing to the re-hospitalizations (OR, 4.61; 95\% CI, 1.68-13.19; $\mathrm{P}<0.01)$. The $\mathrm{FN}$ rate in an outpatient setting was $18.1 \%(19 / 105)$. In this outpatient setting, 9.5\% (10/105) of the patients experienced FN for the first time. Therefore, there is a continual requirement to educate patients on infection prevention.

In the present study, $9.5 \%(10 / 105)$ of the patients were not able to complete their planned treatment. The numbers of patients unable to complete the treatment were significantly different between the re-hospitalization and non-hospitalization groups (OR, 11.81; 95\% CI, 2.07-99.74; $\mathrm{P}<0.01)$. The reasons why patients were unable to complete treatment were severe infection (5/10), a poor PS (4/10) and heart failure (1/10). Infection has been identified as an important risk factor for the completion of planned treatment. The mean age of the patients who were unable to complete their planned treatment was 80 years (range 63-93 years), which was significantly older compared with the age of the patients who were able to complete their planned treatment $(\mathrm{P}<0.01)$. In the present study, $20.6 \%(28 / 136)$ of all the patients who received $\mathrm{CHOP}$ chemotherapy were $>80$ years, and only $\sim 50 \%$ of them $(13 / 28)$ could be treated in an outpatient setting. From the first cycle, $76.9 \%(10 / 13)$ of the patients were treated with chemotherapy at an $80 \%$ reduced dose, and $38.5 \%(5 / 13)$ of patients were not able to complete their planned treatment. Age was not identified as an independent risk factor for re-hospitalization and the incidence of FN in the present study. However, Lymam et al (5) and Salar et al (16) reported that an older age was an independent risk factor for the occurrence of FN. Therefore, elderly patients may require special attention concerning infection prevention.

In conclusion, $\sim 90 \%$ of the patients treated with $\mathrm{CHOP}$ chemotherapy experienced a greater- than- grade-3 neutrophil count decrease, and $31.4 \%$ (33/105) of the patients who were able to be treated in an outpatient setting experienced FN in the present study. Although primary prophylaxis with G-CSF was administered in this study, the incidence of FN was still as high as $21.0 \%(22 / 105)$ in cycle 1, which accounted for $53.7 \%$ of all FN events (22/41). These results suggested that the education of patients is required to prevent infections prior to the first chemotherapy cycle. In addition, for patients who require long-term G-CSF and are at risk of unplanned re-hospitalization, Peg-G treatment strategies should be taken into consideration. Therefore, proper supportive therapy and the management of infection are important to safely treat patients undergoing the CHOP regimen in an outpatient setting.

\section{References}

1. Bosly A, Bron D, Van Hoof A, De Bock R, Berneman Z, Ferrant A, Kaufman L, Dauwe M and Verhoef G: Achievement of optimal average relative dose intensity and correlation with survival in diffuse large B-cell lymphoma patients treated with CHOP. Ann Hematol 87: 277-283, 2008.

2. Pettengell R, Schwenkglenks M and Bosly A: Association of reduced relative dose intensity and survival in lymphoma patients receiving CHOP-21 chemotherapy. Ann Hematol 87: 429-430, 2008.

3. Trillet-Lenoir V, Green J, Manegold C, Von Pawel J, Gatzemeier U, Lebeau B, Depierre A, Johnson P, Decoster G, Tomita $\mathrm{D}$, et al: Recombinant granulocyte colony stimulating factor reduces the infectious complications of cytotoxic chemotherapy. Eur J Cancer 29A: 319-324, 1993. 
4. Aapro MS, Bohlius J, Cameron DA, Dal Lago L, Donnelly JP, Kearney N, Lyman GH, Pettengell R, Tjan-Heijnen VC, Walewski J, et al: 2010 update of EORTC guidelines for the use of granulocyte-colony stimulating factor to reduce the incidence of chemotherapy-induced febrile neutropenia in adult patients with lymphoproliferative disorders and solid tumours. Eur J Cancer 47: 8-32, 2011.

5. Lyman GH, Morrison VA, Dale DC, Crawford J, Delgado DJ, Fridman M; OPPS Working Group and ANC Study Group: Risk of febrile neutropenia among patients with intermediate-grade non-Hodgkin's lymphoma receiving CHOP chemotherapy. Leuk Lymphoma 44: 2069-2076, 2003.

6. Pettengell R, Bosly A, Szucs TD, Jackisch C, Leonard R, Paridaens R, Constenla M and Schwenkglenks M; Impact of Neutropenia in Chemotherapy-European Study Group (INC-EU): Multivariate analysis of febrile neutropenia occurrence in patients with non-Hodgkin lymphoma: Data from the INC-EU prospective observational European neutropenia study. Br J Haematol 144: 677-685, 2009.

7. Smith TJ, Khatcheressian J, Lyman GH, Ozer H, Armitage JO, Balducci L, Bennett CL, Cantor SB, Crawford J, Cross SJ, et al: 2006 update of recommendations for the use of white blood cell growth factors: An evidence-based clinical practice guideline. J Clin Oncol 24: 3187-3205, 2006.

8. Oken MM, Creech RH, Tormey DC, Horton J, Davis TE, McFadden ET and Carbone PP: Toxicity and response criteria of the Eastern Cooperative Oncology Group. Am J Clin Oncol 5: 649-655, 1982

9. Armitage JO: Staging non-Hodgkin lymphoma. CA Cancer J Clin 55: 368-376, 2005.

10. Aapro MS, Cameron DA, Pettengell R, Bohlius J, Crawford J, Ellis M, Kearney N, Lyman GH, Tjan-Heijnen VC, Walewski J, et al: The European Organisation for Research and EORTC guidelines for the use of granulocyte-colony stimulating factor to reduce the incidence of chemotherapy-induced febrile neutropenia in adult patients with lymphomas and solid tumours. Eur J Cancer 42: 2433-2453, 2006.

11. Smith TJ, Khatcheressian J, Lyman GH, Ozer H, Armitage JO, Balducci L, Bennett CL, Cantor SB, Crawford J, Cross SJ, et al: 2006 update of recommendations for the use of white blood cell growth factors: An evidence-based, clinical practice guideline. J Clin Oncol 24: 3187-3205, 2006.

12. Balducci L, Al-Halawani H, Charu V, Tam J, Shahin S, Dreiling L and Ershler WB: Elderly cancer patients receiving chemotherapy benefit from first-cycle pegfilgrastim. Oncologist 12: 1416-1424 2007.
13. Case DC Jr, Desch CE, Kalman LA, Vongkovit P, Mena RR, Fridman M and Allen B: Community-based trial of R-CHOP and maintenance rituximab for intermediate- or high-grade non-Hodgkin lymphoma with first-cycle filgrastim for older patients. Clin Lymphoma Myeloma 7: 354-360, 2007.

14. Crawford J,Dale DC, Kuderer NM, Culakova E, Poniewierski MS, Wolff D and Lyman GH: Risk and timing of neutropenic events in adult cancer patients receiving chemotherapy: The results of a prospective nationwide study of oncology practice. J Natl Compr Canc Netw 6: 109-118, 2008.

15. Pettengell R, Schwenkglenks M, Leonard R, Bosly A, Paridaens R, Constenla M, Szucs TD and Jackisch C; Impact of Neutropenia in Chemotherapy-European Study Group (INC-EU): Neutropenia occurrence and predictors of reduced chemotherapy delivery: Results from the INC-EU prospective observational European neutropenia study. Support Care Cancer 16: 1299-1309, 2008.

16. Salar A, Haioun C, Rossi FG, Duehrsen U, Pettengell R, Johnsen HE, Jaeger U, Verhoef G, Schwenkglenks M, Bacon $\mathrm{P}$, et al: The need for improved neutropenia risk assessment in DLBCL patients receiving R-CHOP-21: Findings from clinical practice. Leuk Res 36: 548-553, 2012.

17. Mayordomo JI, López A, Viñolas N, Castellanos J, Pernas S, Domingo Alonso J, Frau A, Layola M, Antonio Gasquet J and Sánchez J; ENIA Study Group: Retrospective cost analysis of management of febrile neutropenia in cancer patients in Spain. Curr Med Res Opin 25: 2533-2542, 2009.

18. Lyman GH and Delgado DJ: Risk and timing of hospitalization for febrile neutropenia in patients receiving CHOP, CHOP-R, or CNOP chemotherapy for intermediate-grade non-Hodgkin lymphoma. Cancer 98: 2402-2409, 2003.

19. Morstyn G, Foote MA, Walker T and Molineux G: Filgrastim (r-metHuG-CSF) in the 21st century: SD/01. Acta Haematol 105: 151-155, 2001.

20. Lord BI, Woolford LB and Molineux G: Kinetics of neutrophil production in normal and neutropenic animals during the response to filgrastim (r-metHu G-CSF) or filgrastim SD/01 (PEG-r-metHu G-CSF). Clin Cancer Res 7: 2085-2090, 2001. 